\title{
PENGIKISAN BAHASA DALAM MASYARAKAT JAWA Catatan tentang Proses Kepunahan Bahasa Jawa
}

\author{
Hendarto Supatra \\ Fakultas Ilmu Budaya Universitas Diponegoro Semarang
}

\begin{abstract}
Will Javanese language die in ten to fifteen years to go? The answer tends to be "no". How about in coming two or three generations? The answer will be "possibly yes". The fact, since the day of the independence declaration of the Republik of Indonesia, Javanese language has been undergoing a process what may be called language obsolescent or language replacement, or language demise or language death, in a certain degree. There are at least two reasons to support the prediction on that undesired destiny of the Javanese language in next generation periods. First, in this global era caused by the speed development of science and technology especially in transportation and communication, half of the total languages in the world, around 6000 languages, were dead in the past three centuries and ten languages will die every year. Some local languages have been replaced by, not many but powerful and dominant international languages, like English, and by national language like Indonesian in Indonesia. In Semarang and possibly other cities in Java not including Surakarta and Yogyakarta, Javanese people rarely speak krama, in a situation where it should be, while at least in rural area where ngoko was used, now in certain domains are replaced by Indonesian language significantly, where the speakers are young generation. Javanese language, said many people, has been a foreign language taught in elementary school to senior high school. Today, however, in informal situation among those who are familiar one with another, especially between people from lower status, lower Javanese or ngoko is still used in many places, and full Javanese (ngoko and krama) is still used in areas such as Demak, Purwodadi, Salatiga, and Pekalongan. This phenomena will unlikely change in 5 to 10 years to go. But no one, I think, will dare to guarantee if people use one to two generations as criterion. Now people with different backgrounds have been without hesitant to choose Indonesian as their children's mother tongue since 30 to 35 years ago, with many different reasons. Two among other reasons are, first, for their children's success in school, and second, parents don't want their children speak with them using ngoko, so it seems no choice but Indonesian. How about with krama? It is not a secret any more that some parents in Semarang city tend not having communicative competence to speak krama. Entering global era in this reformation period, English language has been used everywhere in this country although actually people still use Indonesian, so what I mean is that that is a case of code-mixing. What is important to note here is that people's attitude toward that foreign language can be considered to endanger the status of Indonesian because of the high status of that foreign language in the situation only few people speak standard Indonesian, an Indonesian prestigious variety. It is clear without saying with the fate of Javanese language if no people are aware with the situation. This article proposes some suggestions to anticipate the situation described above beside the fact that Javanese people are still proud with their culture.
\end{abstract}

Key Words: contact Linguistics, Lingua Franca, language attrition, Javanese language. 


\section{Pendahuluan}

Purwo dalam artikelnya yang berjudul "Pengembangan Bahasa Daerah: Kekuatan Politik dan Kepentingan Pendidikan" (2009: 203) mencatat bahwa separo di antara 6000 bahasa di dunia ini terancam punah, oleh karenanya, demikian lanjutnya, sidang umum UNESCO tahuan 1999 menetapkan tanggal 21 Februari sebagai Hari Bahasa Ibu Internasional, berlaku sejak 21 Februari 2000. Hal yang "buruk" itu diperkirakan masih akan berlanjut hingga nanti pada abad mendatang dikawatirkan $95 \%$ bahasa-bahasa itu akan punah. Pada saat ini rata-rata 10 bahasa mengalami kepunahan dalam satu tahun. Dalam nada yang sama Winford (2003: 257) mencatat bahwa "Roughly half of the world's known languages have disappeared within the last 500 years. Hundreds more are in danger of dying." Indonesia yang menduduki urutan kedua dalam hal jumlah bahasa di dunia yakni 706 bahasa, dan urutan pertama diduduki Papua Nugini dengan 867 bahasa, tentu merupakan wilayah yang paling rawan ketika misalnya terbukti bahwa bahasa Jawa yang merupakan penopang budaya adhi luhung itu pun tergolong yang sedang mengalami proses kemunduran atau malah, menurut Sugono (2005), "kurang diperhatikan oleh penuturnya sejak diberlakukannya otonomi daerah."

Mengapa terjadi kecenderungan kepunahan bahasa-bahasa? Jawabnya agaknya adalah bahwa di era modern ini kontak antarbahasa atau antarbangsa menjadi semakin intensif. Di masa silam ketika lautan, selat, gunung, sungai, hutan, masih merupakan hambatan untuk jalinan komunikasi kecenderungan yang terjadi tentulah bahasa akan terbiak menjadi dialek-dialek, dan dialek-dialek itu akan menjadi bahasa-bahasa baru. Dengan semakin canggih alat-alat transportasi dan alat komunikasi seperti radio, TV, telepon, komputer, maka apa-apa yang semula merupakan hambatan kini berubah fungsi menjadi penghubung. Laut menjadi panghubung antarbenua atau antarpulau, selat antarpulau, sungai dinetralkan oleh jembatan, gunung juga bukan lagi hambatan karena ada pesawat udara, dan boleh dikatakan jarak ruang dan waktu juga dapat diatasi lewat telepon atau pun internet. Di era sekarang ini, banyak masyarakat yang semula monobahasawan yakni pengguna bahasa daerah sebagai bahasa ibu dan satu-satunya, sekarang menjadi dwibahasawan atau malah multibahasawan, karena mereka juga menjadi penutur bahasa nasional bahkan bahasa internasional, padahal bahasa atau bahasa-bahasa itu juga berfungsi sebagai penunjuk identitas, termasuk identitas kegengsian orang per orang atau masyarakat. Tentu saja orang akan lebih merasa bangga dikategorikan internasionalis daripada nasionalis, atau pun lokalis. Dalam konteks semacam ini bahasa Inggris misalnya bisa menjadi ancaman bagi bahasa Indonesia, dan keduanya atas bahasa daerah. Tentu saja hal yang demikian itu tidak mesti terjadi asalkan ada upaya-upaya yang dilakukan secara memadai. Secara jelas Purwa (2009: 203), menulis sebagai berikut. "Bagaimana nasib bahasa daerah di masa depan? Itu 
tergantung pada bagaimana kekuatan politik yang menyekitarinya, dan seberapa sadar kita akan kepentingan bahasa daerah untuk pendidikan anak-anak kita.”

Sejak sekitar revolusi kemerdekaan para pemimpin bangsa ini sangat menyadari akan tantangan utama negara - yang meliputi wilayah bekas jajahan Belanda ini, suatu wilayah yang amat luas dengan kebhinekaan budaya yang ditopang atau terbukti oleh banyaknya bahasa - yakni nasionalisme. Soal ke-eka-an yang masih berada dalam taraf kesadaran politik dan yang masih terus diperjuangkan untuk menjadi kesadaran budaya, belum sepenuhnya selesai. Inilah sebabnya ada semacam kesengajaan yang tanpa keraguan, dan sejak peristiwa Sumpah Pemuda lalu Revolusi Kemerdekaan, kebijakan politik dengan mengutamakan bahasa nasional itu telah menyebabkan meningkatnya penguasaan bahasa nasional sebagai bahasa kedua dan pemakaian bahasa nasional tersebut pada sejumlah ranah pemakaian bahasa yang sebelumnya diisi oleh bahasa daerah. Sementara itu saat ini, yakni di era reformasi yang ditandai oleh adanya kebebasan berpendapat dan berbuat, demikian menurut Moeliono (2009), oleh karena bangsa Indonesia untuk sebagian besar tidak terlalu terdidik dalam penggunaan bahasa Indonesia, maka yang terjadi ialah bahwa ragam "gaul" jauh lebih popular daripada ragam bahasa baku. Dalam hal ini, maksud Moeliono ialah bahwa dalam keadaan yang demikian itu kebanggaan atas bahasa Indonesia belum sungguhsungguh terwujud. Olehnya, demikian lanjutnya, "Dalam konteks kebahasaan, globalisasi membuka pintu bagi bahasa global masuk dengan bebas ke dalam masyarakat yang bahasa nasional atau bahasa resminya belum mantap. Yang kuat menang yang lemah harus meminggir (bandingkan Alwasilah, 2004). Sekarang ini dalam dunia niaga, iklan misalnya, banyak menggunakan kosakata Inggris. Dengan iklan yang demikian itu seolah pemilik atau calon pemilik barang atau pun jasa yang ditawarkan menjadi terangkat harga dirinya. Tidakkah yang demikian itu akan meminggirkan lagi bahasa daerah yang sudah meminggir ketika sebelumnya sudah terjadi proses peminggiran dikarenakan oleh pengutamaan bahasa nasional yang kemudian ditopang pula oleh fasilitas untuk belajar bahasa nasional secara berlimpah-limpah melalui radio, TV, majalah, surat khabar dan pendidikan sejak SD hingga Perguruan Tinggi. Ya, tetapi sebenarnya apakah kerugian kita seandainya keadaan seperti sekarang ini terus berlanjut?

\section{Kepunahan Bahasa Harus Dicegah}

Ada banyak alasan yang masuk akal untuk dikemukakan, satu di antaranya yang terpenting ialah bahwa tiap-tiap budaya atau bahasa sebenarnya merupakan cara pandang yang unik. Bukankah memang benar ketika dikatakan bahwa tak seorangpun (atau suatu masyarakat) pernah melihat apa pun tidak dari posisi tertentu. Realitas yang ditangkap oleh seseorang atau masyarakat budaya tertentu selalu bersifat parsial, dan justru karena itu satu dengan yang lain saling memerlukan. Tiap-tiap bahasa atau kebudayaan adalah jendela yang 
melaluinya orang melihat sisi tertentu dari realitas. Kraft (1990), seorang linguis, antropolog, dan sekaligus teolog, yang bertahun-tahun menghabiskan waktunya di Benua Afrika, menulis atas dasar pengalaman kerjanya itu sebagai berikut.

Cultures pattern perceptions of reality into conceptualizations of what reality can or should be, what is to be regarded as actual, probable, possible, and impossible. These conceptualizations form what is termed the "worldview" of the culture. The worldview is the central systematization of conceptions of reality to which the members of the culture assent (largely unconsciously) and from which stems their value system. The worldview lies at the very heart of culture, touching, interacting with, and strongly influencing every other aspect of the culture (Kraft, 1990:53).

Padahal, seluruh kekayaan kebudayaan itu menyatu atau tersimpan dalam bahasa yang sekaligus merupakan salah satu wujud kebudayaan itu sendiri. Tentang sentralnya bahasa dalam kebudayaan ini, Alisjahbana (dalam Halim, 1981) menulis sebagai berikut.

It is so often said that the language represents the soul of the people, the essence of its culture. Indeed there is no other culture element which expresses the totality of more comprehensively and exactly than the language. The vocabulary of a language, for example, represents the whole spiritual and material richness of a culture (Halim, 1981: 60).

Punahnya suatu bahasa dengan sendirinya sama artinya dengan hilangnya suatu cara pandang tertentu atas realitas atau semesta ini. Dengan cara ungkap yang berbeda, kurang lebih 2500 tahun yang lalu, idea atau pemikiran seperti di atas sudah pernah diungkapkan orang dalam bentuk syair berikut ini.

\section{Inner Dept}

To see is to be blinded by colours; to hear is to be deafened by sound; to taste

Is to be dulled by flavours. Precious things are distracting. Thinking is confused by

Searching; doing is undone by hurrying.

Therefore, quietly attend to what is inside but not what is outside, to what is by

Subtle but not what is conspicuous. Be guided by the inner not by the outer,

Inner sense but not outer form. Attend only to form and the inner depth is undiscovered.

Teach without expecting praise, without fear of censure. Be guided by neither

Approval nor disapproval. Learn without expecting benefit. Temper desire.

Look for the simple in the complicated, the ordinary in the extraordinary, the Serene in the hectic, the empty in the full, the greatest in the least. 
(Syair ke-12 dari Kitab Dao De Jing dimuat dalam Grigg, 1994: 23).

Sebenarnya bukan hanya dengan penglihatan, pendengaran, perabaan atau pun pencicipan, orang tidak sampai sungguh-sungguh menyentuh realitas, melainkan juga dengan pikirannya atau dengan bahasanya orang tidak akan menyentuh realitas sebagaimana adanya. Pada halaman xiii, Grigg menulis sebagai berikut.

Anyone who thoughtfully uses language should realize that words are not a replication of experience but a representation. Language does not replicate experience although it may replicate what is thought to have been experience which is quite another thing. Words always create vicariousness.

Konteks fisik, pengaruh sejarah, dan tokoh-tokoh kuat sepanjang sejarah telah menyebabkan masyarakat tertentu memfokuskan diri pada aspek-aspek tertentu dari realitas. Demikianlah antara lain dapat dicontohkan sebagai berikut. Oleh karena orang Barat (Eropa, Amerika) berada di depan dalam hal ilmu dan teknologi, maka dalam era global ini, tidak ada pilihan bagi negara-negara berkembang, kecuali harus belajar dan memahami sejumlah konsep yang disimboli dengan sejumlah kosakata moderen: handphone, lap top, radio, TV, paradigma, inkulturasi, akulturasi, enkulturasi, pragmatic, pragmatism, dsb. Sungguh pun demikian, orang Inggris masih harus menambah jumlah halaman kamus mereka demi predikat kamus lengkap misalnya, dengan kosakata berikut ini, kecuali mereka siap untuk selalu menerjemahkannya. Kata-kata yang dimaksud adalah, onde-onde, rendang, rambutan, duren, degan, cengkir, bluluk, kenthos; mencep-mencep, kimplah-kimplah, ndeprok, nglesot, mlipir; ujuk-ujuk, makjenggelek, njedodot, njenggirat, njenggureng; nggendong, manggul, mikul, nyunggi, nggawa, nyangking, nyengkiwing, nglarak, ngindit, ngempit, dsb.

Dalam bahasa Inggris kalimat "He eats fried rice" mengandung informasi konteks waktu tertentu. Dengan makna yang kurang lebih sama kalimat itu bisa diubah pada unsurunsur tertentunya bisa menghasilkan informasi konteks waktu yang berbeda-beda, seperti berikut. "He is eating fried rice", "He has eaten fried rice", "He ate fried rice", "He had eaten fried rice", "He will eat fried rice". Model ketatabahasaan seperti ini tidak dikenal dalam bahasa Indonesia maupun bahasa Jawa. Akan tetapi harus diingat juga bahwa bahasa Inggris tidak sekaya bahasa Jawa dalam menangkap dan mengkonsepsikan variasi kata kerja yang berarti "makan" itu. Perhatikan contoh berikut.

Deweke mangan sega goreng.

Deweke mbadok sega goreng.

Deweke nyosor sega goreng.

Deweke nguntal sega goreng.

Panjenengane dahar sega goreng.

Piyambakipun neda sega goreng. 
Bahasa Inggris atau malah bahasa apa pun di dunia sepertinya tidak ada yang menandingi bahasa Jawa dalam kepemilikannya akan variasi kata yang didasarkan pada latar belakang penutur dan lawan tuturnya, serta suasana hati atau keterkendalian emosi penuturnya. Bentuk morfologis seperti abang-abang "merah-merah", ijo-ijo "hijau-hijau", kuneng-kuneng "kuning-kuning" yang bukan hanya menunjuk warna melainkan juga sebagai penanda jamak untuk nomina yang diterangkannya, juga tidak dikenal dalam bahasa Inggris. Tentu masih ada banyak lagi yang bisa disebut sebagai kekayaan, karena uniknya, bahasa Jawa yang sebenarnya merupakan kekayaan manusia. Bahasa Jawa dalam seni pewayangan itu kaya luar biasa. Sebuah seni berkelas dunia karena mampu memikat penontonnya lebih dari 5 jam, tanpa jeda. Ya, tetapi benarkah bahasa Jawa akan punah? Adakah tanda-tanda ke arah itu? Sebelum mengupas hal tersebut akan terlebih dahulu diketengahkan sebagai pembanding sebuah kasus kepunahan bahasa.

\section{Bahasa Melayu Tionghoa: Kasus Pembanding}

Bahasa Melayu Tionghoa telah punah, benarkah? Terhadap pertanyaan itu, Jakob Sumardjo (2004) menjawab "ya". Pakar sosiologi sastra yang memperhatikan dengan serius sastra Melayu Tionghoa ini, melaporkan hasil kajiannya bahwa jenis sastra ini menghasilkan karyanya yang pertama berupa buku syair yang berjudul Sair Kedatangan Sri Maharaja Siam di Betawi dan berakhir dengan Surat Keputusan Menteri Pendidikan RI tanggal 6 Juli 1966, demikian katanya, ketika sekolah-sekolah berbahasa Tionghoa ditutup dan anak-anak Indonesia Tionghoa didorong untuk belajar di sekolah swasta atau pun negeri yang menggunakan bahasa Indonesia. Lebih lanjut Jakob Sumardjo menulis sebagai berikut.

Dengan keputusan Menteri Pendidikan itu, maka identitas Cina Peranakan di Indonesia berangsur-angsur dilenyapkan. Tentu tidak seluruh identitas budaya mereka lenyap hanya soal bahasa. Tetapi dengan penggunaan bahasa ini, setidak-tidaknya lenyaplah bahasa Melayu-Cina di Indonesia, dan dengan demikian juga jenis kesusastraan mereka (2004: 51).

Jauh sebelum pernyataan Sumardjo di atas yakni pada tahun 1955, Nio Joe Lan pernah menerbitkan sebuah karangan yang diberi judul Perkembangan dan Berachirnja Bahasa Melajoe Tionghoa. Di dalam tulisan itu dinyatakan bahwa Bahasa Melayu Rendah atau Melayu Betawi atau melayu Pasar atau Melayu Tionghoa telah kehilangan hak hidupnya. Generasi muda yang wajib belajar di sekolah yang menggunakan bahasa Indonesia secara otomatis meninggalkan bahasa generasi sebelumnya (Bandingkan Salmon, 1983:105). Berbeda dengan Nio Joe Lan yang boleh dikatakan, pada tahun 1955 itu, baru melihat tandatanda, Sumardjo dengan tegas menyatakan bahwa "Bahasa itu sudah milik masa lampau. Bahasa itu sudah tidak hidup lagi setelah tahun 1966" (2004: 3). Yang sungguh-sungguh mengagumkan ialah prediksi Sutan Takdir Alisjahbana. Dikatakan sebagai prediksi sebab 
pernyataan beliau itu dibuat pada saat bahasa Melayu Tionghua masih dalam masa kejayaannya. Berikut ini pernyataan beliau.

Apabila enam puluh miliun bangsa Indonesia itu sekaliannya telah pernah duduk di bangku sekolah dan mendapat pelajaran yang agak sempurna tentang bahasanya, apabila surat kabar, majalah dan buku2 bahasa Indonesia telah sampai ke tangan segala rakyat Indonesia, apabila dalam segala cabang pergaulan telah berkuasa bahasa Indonesia umum ..., maka dengan sendirinya lenyap haknya bahasa Melayu-Tionghua berdiri sendiri dan berpengaruh seperti sekarang dalam masyarakat di negeri ini (Alisjahbana, 1934: 61).

Tentu wajar saja ketika timbul pertanyaan, mengapa bahasa Melayu Tionghua yang sebenarnya sama dengan bahasa Indonesia yakni bahwa keduanya merupakan variasi bahasa Melayu bisa saling menenggelamkan seperti yang sudah terjadi. Pada masa kejayaan bahasa Melayu Tionghua sebagai bahasa pergaulan, perdagangan, surat khabar, susastra, agama, dan pemerintahan Kolonial, bahasa Melayu Standar yang kemudian berkembang menjadi bahasa Indonesia tersisihkan perannya, dan ketika bahasa Melayu Standar dipromosikan oleh pemerintah Kolonial dan dilanjutkan oleh pemerintah RI dan akhirnya menjadi bahasa dominan, maka Melayu Tionghua pun terpinggirkan dan akhirnya punah. Mengapa tidak terjadi, di mana kedua variasi tersebut hidup secara berdampingan?

Sebelum menjawab pertanyaan yang dalam tulisan ini dinilai sangat krusial karena akan menjadi bahan pembanding sehubungan dengan kajian atas bahasa atau bahasa-bahasa daerah pada umumnya dan bahasa Jawa pada khususnya, akan lebih dahulu diperiksa dalam jarak yang lebih dekat perihal pengertian bahasa Melayu Tionghua ini.

Orang-orang Tionghua, terutama suku Hokian, yang tinggal atau malah lahir di Indonesia dan berdarah campuran dengan orang Sunda atau pun Jawa di pulau Jawa, sejak berabad yang lalu, sebagiannya berbahasa ibu bahasa Sunda atau pun Jawa dan sebagian yang lain berbahasa ibu bahasa Melayu. Untuk jenis yang terakhir ini setidak-tidaknya bisa didapatkan di Jakarta, Surabaya, Semarang, dan kota-kota besar di luar pulau Jawa. Di Yogyakarta dan Surakarta misalnya, bahasa ibu mereka adalah bahasa Jawa; sungguh pun demikian mereka juga menguasai bahasa Melayu. Bahasa Melayu atau lebih spesifik bahasa Melayu Rendah merupakan identitas orang-orang Indonesia Tionghua (Supatra, 2009). Lalu apakah yang dimaksud dengan bahasa Melayu rendah itu?

Orang-orang Indo-Tionghua yang umumnya tidak menguasai bahasa Tionghua sudah tentu bukan penutur jati bahasa Tionghua, padahal agaknya mereka juga tidak merasa sepenuhnya orang Jawa (untuk konteks di Jawa) meskipun leluhur mereka dari garis ibu adalah orang Jawa, maka, demikianlah fakta sejarah, mereka memungut bahasa Melayu 
Rendah yang semula tidak memiliki penutur jati itu, sebagai bahasa ibu mereka. Bahasa Melayu rendah atau Melayu Pasar ini setidaknya telah ada sejak abad ke-17. Bahasa Melayu Rendah yang dimaksud sebenarnya adalah variasi bahasa Melayu yang disebut sebagai Lingua Franca di Nusantara. Pada masa itu, demikian tulis Groeneboer (1995: 23) variasi Melayu jenis ini oleh sementara orang, tidak dianggap sebagai bahasa. Akan tetapi seorang misionaris yang sekaligus juga permerhati bahasa, Velentijn, pada tahun 1724, berhasil melukiskan ciri-ciri variasi Melayu ini, dan kemudian menantang mereka yang tidak menganggap variasi ini sebagai bahasa, dengan membuktikannya lewat usahanya menerjemahkan Kitab Injil ke dalam variasi ini, dan dia memang berhasil. Ada pun gambaran tentang Melayu Rendah itu sebagai berikut.

Kecuali bahasa Melayu-Tinggi, ada juga yang Rendah, yang berasal dari berbagai bangsa dengan bahasanya masing-masing dan dialek masing-masing dan kadang-kadang juga mempergunakan berbagai kata yang berasal dari bahasa Portugis atau dari bahasa lain dicampuradukkan, juga disebut bahasa Katsyokan yaitu bahasa campuran atau bahasa Pasar yang dipergunakan oleh para pedagang antar mereka agar jual beli dapat berjalan lancar dan mereka dapat saling mengerti. Sewajarnyalah bila dalam komunikasi antara beragam bangsa itu, dipergunakan atau disisipkan kata-kata berasal dari bahasa mereka sendiri atau dari bahasa lain yang lebih dikenal daripada bahasa Melayu dan mereka pergunakan pada saatsaat yang dibutuhkan untuk keluar dari kesulitan (Valentijn 1724, II-I:244 dikutip dalam Groeneboer, 1995:24).

Melayu Rendah inilah yang akhirnya menjadi pilihan Belanda untuk kepentingan pemerintahan, Gereja, dan urusan pendidikan, dan demikian pulalah halnya dengan Portugis yang lebih dahulu datang ke Asia Timur. Mudah dibayangkan, sejak itu, yakni sejak difungsikannya Melayu Rendah ini untuk tugas yang bergengsi itu, kemudian juga untuk penerjemahan Alkitab, Melayu Rendah ini mengalami perkembangan yang luar biasa seperti yang terjadi atas bahasa Melayu ketika menjadi bahasa Indonesia dengan fungsi sebagai bahasa pemerintahan dan bahasa pendidikan dari SD sampai dengan Perguruan Tinggi. Dengan demikian sama sekali tidak mengherankan ketika pada taun 20-an abad XX, variasi Melayu ini sempat menjadi bahasa perhubungan utama di Nusantara, bahasa persuratkabaran, bahkan bahasa susastra. Dan pada tahun-tahun itu yakni kwartal pertama abad XX banyak wartawan dan sastrawan yang secara etnis adalah orang-orang Tionghua keturunan meskipun kenyataannya yang menggunakan Melayu Rendah ini adalah mereka yang terdiri dari berbagai etnis yang tinggal di kota-kota dan tergolong orang-orang modern di jamannya. Perihal yang terakhir ini, kesaksian Raden Mas Tirto Adhi Soerjo dalam majalah Medan Prijaji (yang dia pimpin) berikut ini membuktikan bahwa Melayu rendah milik berbagai etnis.

Itoe semoea orang nanti dapat taoe dengan membatja soerat kabar Pembrita Tjoeng Wa sebab ini soerat kabar ada pake bahasa Melajoe rendah, suatu bahasa jang gampang orang 
mengerti dan jang djadi bahasanja sebagian besar pendoedoek di Hindia Nederland (Salmon, 1983: 100).

Bahasa Melayu Tionghua, untuk sekarang ini, orang menyebutnya dialek sosial atau sosiolek yang timbul akibat pengaruh latar belakang etnis penuturnya. Sosiolek ini bisa dikenali identitasnya pada kekhasannya dalam hal digunakannya leksikon Mandarin atau terutama dialek Hokian, dan yang unik mereka itu adalah penutur jati bahasa tersebut. Jadi di satu pihak Melayu Tionghua adalah secabang bahasa Melayu di lain pihak merupakan bahasa ibu (mother tongue) orang-orang Tionghua (keturunan). Seandainya tidak demikian, artinya bahwa penutur Melayu Tionghua ini bukan penutur jati, barang kali sulit diharapkan secabang Melayu ini akan bisa menjadi bahasa persuratkabaran yang dominan waktu itu dan menghasilkan karya sastra yang demikian kaya, dan secara kuantitas juga jauh melangkaui susastra Melayu tinggi (Bandingkan Salmon, 1985: xv, Sumardjo 2004).

Sebagai bahasa ibu, Melayu Tionghua juga mempunyai subsubvarian. Di samping sebagai bahasa perhubungan luas, bahasa perdagangan, persuratkhabaran, susastra, dsb, tentu juga menjadi bahasa sehari-hari tingkat lokal. Inilah sebabnya, di samping adanya ciri-ciri yang menyatukan, bahasa ini juga berbeda dari satu kota ke kota yang lain. Pengamatan yang cermat memang akan bisa membedakan Melayu Tionghua Jakarta dengan Semarang, Bandung, Surabaya, Tegal dan Yogyakarta misalnya. Melayu Tionghua yang dituturkan di Medan sangat sulit dibedakan dari Melayu tinggi (Alisjahbana, 1934: 58). Lalu mengapa secabang Melayu ini bisa punah? Atau, benarkah kini sudah tidak ada lagi Melayu Tionghua itu? Setidaknya, Nio Joe Lan (1962), Jakob Sumardjo (2004), dan Sutan Takdir Alisjahbana (1934) berpendapat demikian. Penulis mempunyai pendapat yang sedikit berbeda. Yang punah itu bukan bahasa Melayu Tionghua melainkan register surat khabar dan register susastranya saja, dan termasuk yang hilang juga adalah perannya sebagai bahasa pergaulan luas dan lebih spesifik lagi untuk fungsi-fungsi serimonial, sedangkan untuk fungsi vernacular secabang Melayu ini masih tetap ada. Bahasa Melayu Tionghua sehari-hari (vernacular) masih tetap bertahan sampai sekarang dan dituturkan oleh Tionghua Peranakan, setidaknya di kota Semarang dan pasti juga di Surabaya, Pasuruhan (Lihat Oetomo, 1987), dan kota lainnya. Di kota Semarang pantas untuk diteliti pengaruh Melayu Tionghua ini terhadap bahasa Indonesia lisan sehari-hari di kota tersebut. Dan penulis ini menduga bahwa Melayu Tionghua Jakarta (Betawi) telah berkembang begitu rupa menjadi variasi bahasa Indonesia popular atau "gaul", yang saat ini oleh kejeliannya, Anton M. Moeliono sempat mengeluhkan situasi yang menunjukkan dominannya bahasa Indonesia ragam gaul (istilah beliau) atau ragam "elou ame gue" itu. Berikut ini pernyataan Moeliono.

Pengaturan dan penertiban selama Orde Baru tentang pemakaian bahasa Indonesia di tempat umum, yang dilandasi berbagai peraturan daerah dan putusan pejabat negara, di era Reformasi ditafsirkan sebagai tindakan pemaksaan. Pemakaian ragam adab dan ragam dasar 
mulai dicampurkan. Batas-batas ranah ragam bahasa mulai kabur. Karena sumber daya manusia Indonesia untuk bagian besar tidak terlalu terdidik dalam penggunaan bahasa Indonesia, mudah ditebak bahwa ragam bahasa "gaul" jauh lebih popular daripada ragam bahasa baku (Moeliono, 2009: 119).

Tentang punahnya atau lebih tepat hilangnya register jurnalistik dan sastra dari bahasa Melayu Tionghua yang sejak tahun 1930-an telah diprediksikan oleh Sutan Takdir Alisjahbana dan terbukti benar itu disebabkan oleh kedudukannya yang ganjil, demikian istilah beliau. Penjelasan mengenai hal ini beliau tulis sebagai berikut.

Berbeda dengan cabang2 bahasa Melayu atau bahasa Indonesia yang lain iapun dipakai sebagai bahasa perhubungan dan pergaulan antara penduduk di kepulauan ini yang ber-lain2an tempatnya, sehingga sebagai bahasa perhubungan ia boleh kita anggap berdiri disisi bahasa Indonesia umum. Jumlah buku, surat kabar dan majalah yang tertulis dalamnya amat besar, menyatakan pengaruhnya yang besar (Alisjahbana, 1934: 59).

Oleh karena peran yang sama itu maka wajar kalau terjadi persaingan yang hebat dan mudah untuk ditebak kalau salah satu di antaranya akan terpinggirkan dan akhirnya punah. Perihal persaingan hebat yang pernah terjadi itu bisa dibuktikan lewat pernyataan penulis produktif saat itu yakni Kwee Tek Hoay yang demikian optimis bahwa Melayu Tionghua akan mengalahkan Melayu tinggi, sebagai berikut.

"Kita pertjaja achirnja bakal kalahken (maksudnya Melayu rendah) dan moesnaken sama sekali bahasa Melajoe Riouw atawa Melajoe Ophuijsen yang sekarang masih dilindoengken Government" (Salmon, 1983:101).

Bahasa Capjai, bahasa gado-gado, adalah ungkapan atau tepatnya serangan dari pihak puris atau yang oleh Alisjahbana disebut kaum guru kolot. Akan tetapi memang beralasan juga, demikian Salmon (1983: 102), ketika ada pihak-pihak yang jengkel melihat kaum minoritas dan bukan pribumi pula telah berhasil menyebarluaskan suatu bahasa perhubungan dengan kedudukan yang demikian mapan.

\section{Nasib Bahasa Jawa}

Membahas kedudukan dan peran bahasa Jawa yang sudah diatur demikian rupa dengan perundang-undangan, sebagai bahasa yang terancam kepunahan, sepertinya mengadaada. Memang benar bahwa variasi Melayu keetnisan seperti Melayu Tionghua di berbagai kota yang ada di Nusantara semakin langka didengar, demikian pula dengan Melayu lokal lainnya seperti Madura, Bali, Ambon dsb. tentu tergilas olah bahasa Indonesia. Mudah dibayangkan sejak pendidikan yang manggunakan bahasa Indonesia, banyaknya stasiun radio dan terutama TV yang menggunakan bahasa Indonesia, nasib yang sama juga dialami oleh berbagai bahasa daerah yang dirasa semakin kurang membanggakan oleh penuturnya. 
Sampai saat ini bahasa Jawa masih terpelihara; digunakan dalam percakapan seharihari, meskipun tidak sesering/sebanyak bahasa Indonesia, bahasa Jawa masih juga didengar lewat radio atau pun TVRI, masih ada majalah Penjebar Semangat, masih banyak lagu-lagu yang dicipta dan setiap hari didengar oleh pekerja-pekerja fisik melalui MP3 player atau pun HP (tertentu yang bisa untuk memutar lagu-lagu). Pendeknya, kedudukan bahasa Jawa di Jawa Tengah misalnya, masih kokoh; masih tak terbayangkan bahwa bahasa yang pernah diidealkan kelayakannya untuk menjadi bahasa Nasional ini akan mengalami kepunahan. Paling yang layak dilakukan adalah mencatat kemunduran-kemunduran kalau memang terjadi. Dan berbicara tentang kemunduran atau kerusakan bahasa atau kepunahan bahasa memang meliputi kepunahan yang terjadi secara mendadak karena semua penuturnya meninggal dunia oleh suatu bencana misalnya, atau kepunahan itu terjadi secara perlahanlahan. Batibo (1992, sebagaimana dikutip oleh Winford, 2003: 258) menulis bahwa "language attrition occurs in several stages which overlap to varying degrees". Tahap pertama atau mula-mula adalah tahap pemakaian bahasa warisan nenek moyang secara monolingual. Tahap kedua adalah tahap penggunaan bahasa lain (B2) untuk kepentingan komunikasi antarmasyarakat beda bahasa. Pada tahap kedua ini bahasa pertama (B1) masih menjadi satu-satunya bahasa untuk ranah keluarga, ranah lingkungan di luar keluarga (tetangga, di jalanan, di pasar, dsb). Tahap ketiga adalah periode lanjutan dari bilingualism bedanya, pada periode ini mulai ada penutur yang menggunakan B2 sebagai bahasa utamanya. Pada tahap kedua dan ketiga, mulai terjadi fenomena diglosia dan alih kode dalam ranah yang dulu hanya digunakan oleh B1. Dan ketika lebih banyak lagi wilayah B1 yang digantikan oleh B2 maka tanda-tanda ke arah kepunahan itu semakin nyata. Pada tahap yang keempat anggota masyarakat itu semakin menunjukkan keterbatasan penguasaan B1. Dan tahap selanjutnya adalah kepunahan bahasa. Untuk mengetahui ada di tahap mana saat ini bahasa Jawa tentu butuh penelitian. Beberapa catatan hasil pengamatan sepintas berikut ini mudah-mudahan bermanfaat untuk menentukan langkah selanjutnya.

Dari pengamatan sepintas dan percakapan dengan sesama pengajar di Fakultas Ilmu Budaya Universitas Diponegoro serta diskusi dengan sejumlah mahasiswa, bisa disimpulkan bahwa kedudukan dan peran bahasa Jawa, terutama ngoko lugu dan kromo lugu masih solid di tingkat kabupaten atau di luar kota Semarang. Di tingkat kecamatan atau pun kelurahan di desa-desa (Jawa Tengah), dalam pemakaian bahasa sehari-hari hampir-hampir bisa dikatakan bahwa masyarakat masih monolingual. Memang benar, dalam suasana formal atau untuk topik pembicaraan tertentu seperti pendidikan, orang menggunakan bahasa Indonesia.

Untuk daerah di luar kota semarang dapat dirasakan bahwa semakin jauh daerah tersebut dari pusat pamakaian bahasa Jawa (Surakarta, Yogyakarta) atau yang dikenal sebagai daerah adoh ratu cedak watu (jauh dari ratu, dekat dengan batu), kualitas bahasa Jawanya semakin menurun. Dalam penelitiannya yang diberi judul Kaidah Penggunaan Ragam 
Krama Bahasa Jawa, Ekowardono, dkk (1993) menulis sebagai berikut, “... seperti di pantai utara Jawa Tengah, banyak kita jumpai penggunaan kaidah tingkat tutur yang terbalikbalik"(1993:3). Berikut ini contoh yang diketengahkannya.

Kula badhe kondur 'Saya akan pulang' yang mestinya Kula badhe wangsul.

Lebih lanjut para peneliti tersebut di atas berpendapat bahwa kurangnya penguasaan kaidah tingkat tutur semacam itu, bagi yang dapat berbahasa Indonesia, demi terhindarkannya status kurang sopan, orang sering beralih kode, menggunakan bahasa Indonesia (Lihat juga Ekowardono 1990: 35-36). Akhirnya, masih pada halaman yang sama, mereka khawatirkan bahwa, "Kalau kebiasaan alih kode itu meluas dan terjadi terus-menerus, dapat dibayangkan bahwa kelestarian bahasa Jawa terancam". Dan agaknya prediksi mereka itu sekarang sudah menjadi kenyataan untuk kota Semarang dan mungkin juga telah terjadi di kota-kota pesisir utara Jawa. Jadi kedwibahasaan yang seimbang sudah terjadi.

Terdapat beberapa hal lain yang pantas dicatat sehubungan dengan kontak bahasa yang terjadi di Semarang dan kota-kota pesisir utara Jawa Tengah, yakni bahasa Inggris, bahasa Indonesia, dan bahasa Jawa, sebagai berikut.

1. Terjadi peningkatan penggunaan bahasa (kosakata Inggris) dalam pertemuan resmi, di tempat-tempat umum (terutama iklan), dan di media elektronik. Bahasa asing ini dianggap sangat membanggakan.

2. Sejak dahulu orang-orang Indonesia Tionghua adalah penutur jati atau berbahasa ibu bahasa bahasa Melayu/Indonesia. Sementara itu anak-anak yang saat ini berumur sekitar 30 sd 35 tahun dari keluarga suku Jawa kelas menengah dan tinggi (dosen misalnya) diperkirakan lebih dari 50\% adalah penutur jati bahasa Indonesia meskipun mereka rata-rata juga berbahasa Jawa ngoko dengan teman sebayanya. Sementara itu beberapa di antara mereka mengaku risih atau merasa aneh ketika menggunakan krama dan untuk kepentingan menghormati lawan bicara selalu digunakan bahasa Indonesia. Fenomena ini sudah terjadi sejak dulu dan terus meningkat. Sudah sejak awal abad kedua puluh, demikian tulis Sudaryanto (1991: 4), pemakaian rapi unggah-ungguh itu tidak pernah dilakukan secara baik. Lebih lanjut Uhlenbeck (1982: 330) yang dikutip pula oleh Sudaryanto, menulis, "Sampai-sampai sebelum perang dunia kedua, masyarakat Jawa dari golongan atas biasa beralih ke bahasa Melayu atau bahasa Belanda untuk menghindari pemakaian bahasa ibu mereka dan untuk membebaskan diri mereka dari kesopanan berbahasa". Lebih lanjut tentang hal ini bisa dibaca Kartoamidjojo (1962) dan Poedjosoedarmo (1979).

3. Pada saat ini penulis tidak pernah melihar surat kabar berbahasa Jawa sementara itu majalah popular berbahasa Jawa yang kadang masih kelihatan dibaca di kampus FIB Universitas Diponegoro sepertinya tinggal Penjebar Semangat dan Jayabaya. 
4. Kongres bahasa Jawa dari waktu ke waktu diselenggarakan dalam atau menggunakan bahasa Indonesia. Penulis menanggapi hal tersebut sebagai wajar-wajar saja sampai suatu saat dibuat terkejut ketika seorang teman dari Jerman, dosen di STT Abdiel, yang dalam salah satu kongres itu membacakan makalahnya yang ditulis dalam bahasa Jawa (konon merupakan satu-satunya makalah berbahasa Jawa) menyatakan bahwa dalam pengalamannya, baru sekarang dia melihat kongres bahasa tertentu tidak menggunakan bahasa tertentu itu.

5. Salah satu ciri bahasa yang beradab tinggi adalah bahasa yang telah dibukukan kaidah-kaidah bakunya, dan hasilnya adalah sebuah tata bahasa baku. Bahasa Jawa telah memiliki tata bahasa baku semacam itu yang ditulis dengan tujuan tertentu "yakni memberi pedoman dan kemudahan demi pemantapan dan pendinamisan pemakaian" (Sudaryanto, 1991: 2) atau "untuk memeberikan pedoman pasti tentang penggunaan bahasa Jawa bagi para penggunanya, baik sebagai bahasa pergaulan sehari-hari maupun untuk suatu karya penulisan" (Gubernur Jawa Tengah, Kata sambutan pada buku tsb.), anehnya, setidaknya menurut subjektivitas penulis ini, buku pedoman itu ditulis dalam bahasa Indonesia.

6. Sejumlah mahasiswa dari keluarga Jawa yang oleh satu dan lain hal harus tinggal di wilayah yang tidak berbahasa Jawa (Jakarta, Jawa Barat, Medan, dll.) berbahasa ibu bahasa Indonesia. Anak-anak dari orang tua campuran, yang salah satunya (suami atau istri) orang Jawa juga senderung menjadi penutur jati bahasa Indonesia bukan bahasa Jawa.

7. Dosen senior di FIB Undip, dalam suasana informal akan menggunakan ngoko terhadap rekan juniornya sementara itu dosen junior cenderung enggan membalas dengan ngoko namun alih-alih ragam dengan menggunakan bahasa Indonesia.

\section{Simpulan}

Bahasa Jawa bukan secabang bahasa Melayu. Bahasa Jawa juga tidak akan menjadi bahasa perhubungan antarpulau atau pun antaretnis di Nusantara ini. Bertolak dari fakta tersebut jelas bahwa kedua bahasa, yakni bahasa Jawa dan bahasa Indonesia, tidak akan mengalami konflik seperti yang pernah terjadi antara bahasa Indonesia atau Melayu standar dengan Melayu Tionghua. Kalau pun konflik terjadi, itu tidak terjadi pada wilayah nasional melainkan regional yakni di wilayah yang masyarakatnya berbahasa utama bahasa Jawa.

Idealnya memang seluruh rakyat Indonesia ini menjadi penutur bahasa Indonesia yang baik, akan tetapi tanpa campur tangan pemerintah dan masyarakat pemerhati bahasa yang terjadi adalah proses peminggiran yang terus berlanjut atas bahasa daerah pada umumnya dan ternyata termasuk ke dalamnya adalah bahasa Jawa yang kaya dan layak dilestarikan itu. 
Sementara orang memang ada yang berpikir bahwa kekawatiran semacam itu timbul karena orang terlalu dipengaruhi oleh cara berpikir yang kategorial; terlalu menarik garis batas yang tegas antara bahasa daerah, bahasa nasional, dan bahasa asing (Lihat Oetomo dalam Alwi dan Sugono, 2000: 91). Padahal semenjak masyarakat Jawa menjadi masyarakat bilingual, bahkan multilingual, maka ketiga bahasa itu akan berubah menjadi unsur-unsur dari sebuah kode saja. Dengan kata lain repertoar bahasa masyarakat Jawa itu meliputi bahasa-bahasa tersebut. Sebagai contoh, bukankah seringnya digunakan bahasa Indonesia bersama-sama dengan Jawa ngoko dikarenakan, untuk masyarakat kelas tertentu dan dalam kontek situasional tertentu, bahasa Indonesia telah menjadi salah satu pilihan antara bahasa Indonesia dengan bahasa Jawa krama. Dalam penyatuan bahasa Indonesia dan bahasa Jawa ngoko sehingga membentuk suatu kode itu bukan hanya bahasa Jawa yang berubah atau terpengaruh. Saling pengaruh itu terjadi dan oleh karena banyaknya dan dominannya orang Jawa di negeri ini maka tidak mengherankan ketika terdengar keluh kesah atau malah protes dari para penutur bahasa Melayu bahwa manjadi bahasa Indonesia itu bahasa Melayu telah mengalami proses "Javanisasi."

Tidak mudah untuk menyanggah pendapat di atas ketika kebijakan politik cenderung berpihak ke arah demokrasi "yang lebih menguatkan masyarakat kewargaan (civil society)", menurut pendapat Oetomo (2000: 92), “dengan meletakkan negara pada proporsinya sebagai fasilitator, coordinator dan system penunjang belaka". Sungguh pun demikian, saya percaya, bahwa tak seorang pun, selagi mampu, akan tinggal diam di hadapan realitas yang tercermin pada pernyataan yang dikutip oleh Crystal (2000: viii) berikut ini.

There is agreement among linguists who have considered the situation that over half of the world's language are moribund, i.e. not effectively being passed on to the next generation. We and our children, then, are living at the point in human history where, within perhaps two generations, most languages in the world will die out.

Pelestarian bahasa Jawa tidak harus diartikan sebagai pemurnian. Seperti apa pun wujud usaha itu mesti diawali dengan kegiatan apa pun yang bisa membangkitkan kebanggaan dan kecintaan terhadap bahasa dan budaya Jawa dan sekaligus disadari pula nilainya sebagai sumber pemerkaya budaya nasional bahkan internasional. Beberapa wujud kegiatan itu barangkali sebagai berikut.

1. Mengadakan surat kabar berbahasa Jawa dan menambah jumlah majalah berbahasa Jawa yang ada. Media cetak itu harus sedemikian rupa dikerjakan sehingga mampu menumbuhkan minat dan rasa ingin tahu orang yang setidaknya selevel dengan media yang berbahasa Indonesia. 
2. Memberi alasan yang tepat terhadap para pengusaha agar menggunakan juga ungkapan atau pun kosakata bahasa Jawa pada merek dagang dan iklan yang mereka buat.

3. Mendorong para cendekiawan untuk sesekali menulis dan berbicara dalam situasi formal (termasuk mengajar) menggunakan bahasa Jawa.

4. Mendorong para seniman terutama sastrawan yang telah diakui mutu karyanya dalam bahasa Indonesia untuk menulis juga dalam bahasa Jawa.

Barangkali demikianlah, antara lain, yang bisa dilakukan, dan untuk itu Pemerintah dan siapa pun yang berpihak kepada keberbagaian (kaum pluralis) bisa melakukan apa pun juga tanpa harus melampaui batas sebagai fasilitator, koordinator, dan penopang atau pun penunjang.

\section{Daftar Pustaka}

Alisjahbana, Sutan Takdir. 1981. "Language Modernization And Nation Building," dalam Amran Halim (ed.), Bahasa dan Pembangunan Bangsa. Jakarta: Pusat Pembinaan dan Pengembangan Bahasa, Departemen Pendidikan dan Kebudayaan.

. 1934, 1957. "Kedudukan Bahasa Melayu-Tionghua," dalam Alisjahbana, Dari Perjuangan dan Pertumbuhan Bahasa Indonesia. Jakarta: Penerbit Dian Rakyat.

Penerbit Dian Rakyat.

1957. Dari Perjuangan dan Pertumbuhan Bahasa Indonesia. Jakarta:

Alwasilah, A. C., 2004. "Bahasa Inggris dalam Modernisasi Bangsa: Ancaman terhadap Bahasa Nasional?” dalam K. E. Sukamto (ed.).

Alwi, Hasan dan Dendy Sugono. 2000. Politik Bahasa. Jakarta: Departemen Pendidikan Nasional.

Crystal, David. 2000. Language Death. Cambridge: Cambridge University Press.

Ekowardono, B. Karno (dkk.), 1993. Kaidah Penggunaan Ragam Krama Bahasa Jawa. Jakarta: Departemen Pendidikan dan Kebudayaan.

Grigg, Ray. 1994. The Tao of Being: Lao Tzu's Tao Te Ching Adapted for a New Age. Singapore: S. S. Mubaruk \& Brothers Pte. Ltd.

Groeneboer, Kees. 1995. Jalan ke Barat, Bahasa Belanda di Hindia Belanda, 1600 - 1950, Sejarah Politik Bahasa. Jakarta: Erasmus Taalcentrum.

Halim, Amran (ed.) 1981. Bahasa dan Pembangunan Bangsa. Jakarta: Pusat Pembinaan dan Pengembangan Bahasa, Departemen Pendidikan dan Kebudayaan.

Kartoamijdjojo, R. 1962. Unggah-ungguhing Basa. Bandung: Ganaco N. V. 
Kraft, Charles H. 1990. Christianity in Culture: Study in Dynamic Biblical Theologizing in Cross Cultural Perspective. New York: Orbis Books.

Lan, Nio Joe. 1962. Sastera Indonesia-Tionghua. Jakarta: Gunung Agung.

Moeliono, Anton M. 2009. "Bahasa Indonesia di dalam Era Reformasi dan Globalisasi," dalam P. Ari Subagyo dan Sudartomo Macaryus (Ed.), Peneroka Hakikat Bahasa. Yogyakarta: Penerbit Universitas Sanata Dharma.

Oetomo, Dede. 1987. The Chinese of Pasuruhan: Their Language and Identity. The Australian National University. . 2000. "Penelitian Bahasa dalam Kerangka Politik Bahasa," dalam Hasan Alwi dan Dendy Sugono. Politik Bahasa. Jakarta: Departemen Pendidikan Nasional.

Poedjosoedarmo, Soepomo (dkk.) 1979. Tingkat Tutur Bahasa Jawa. Jakarta: Pusat Pembinaan dan Pengembangan Bahasa, Departemen Pendidikan dan Kebudayaan.

Purwo, Bambang Kaswanti. 2009. "Pengembangan Bahasa Daerah: Kekuatan Politik dan Kepentingan Pendidikan," dalam P. Ari Subagyo dan Sudartomo Macaryus (Ed.), Peneroka Hakikat Bahasa. Yogyakarta: Penerbit Universitas Sanata Dharma.

Salmon, Claudin. 1985. Sastra Cina Peranakan dalam Bahasa Melayu. Diterjemahkan oleh Dede Oetama. Jakarta: PN Balai Pustaka. . 1985. "Apakah dari Sudut Linguistik Istilah Bahasa Melayu-Tionghua Dapat Diterima?” dalam Citra Masyarakat Indonesia. Jakarta: Percetakan Grafitas.

Subagyo, P. Ari dan Sudartomo Macaryus (Ed.). 2009. Peneroka Hakikat Bahasa. Yogyakarta: Penerbit Universitas Sanata Dharma.

Sudaryanto (Peny.). 1991. Tata Bahasa Baku Bahasa Jawa. Yogyakarta: Duta Wacana University Press.

Sugono, Dendy. 2005. Pusat Bahasa. Jakarta: Pusat Bahasa Departemen Pendidikan dan Kebudayaan.

Sumardjo, Jakob. 2004. Kesusastraan Melayu Rendah, Masa Awal. Yogyakarta: Gelas Press.

Supatra, Hendarto. 2009. "Bahasa Melayu Sebagai Identitas Orang Indonesia Tionghua," dalam P. Ari Subagyo dan Sudartomo Macaryus (Ed.), Peneroka Hakikat Bahasa. Yogyakarta: Penerbit Universitas Sanata Dharma.

Uhlenbeck, E. M. 1982. Kajian Morfologi Bahasa Jawa. Diterjemahkan oleh Sunarjati Djajanegara. Seri ILDEP. Jakarta: Penerbit Djambatan. Publishing.

Winford, Donald. 2003. An Introduction to Contact Linguistics. Oxford: Blackwell 